\title{
Loss of Lever Press-Related Firing of Rat Striatal Forelimb Neurons after Repeated Sessions in a Lever Pressing Task
}

\author{
Regina M. Carelli, Martin Wolske, and Mark O. West \\ Department of Psychology, Rutgers University, New Brunswick, New Jersey 08903
}

Lateral striatal neurons that fire phasically in relation to active movement of the contralateral forelimb (determined via daily sensorimotor examination) were studied during acquisition of cued lever pressing. Rats were trained to lift the contralateral forepaw from the floor to press a lever in the presence of a tone. The tone was presented 70 times per day (session) for 18 consecutive days. All animals acquired the task, evidenced by gradual improvements across sessions and eventual asymptotic levels in tone discrimination, reaction time, and efficiency of the lever press. Forelimb neurons fired in relation to the lever press during early sessions of acquisition but not after repeated sessions on the task. This difference in firing could not be attributed to differences in forelimb movements during lever pressing or to sampling from different populations of neurons in early versus late sessions. In view of evidence that striatal damage impairs acquisition of motor skills, the change in firing suggests that the striatal activity present in early sessions may be necessary for the acquisition of, but not the automatic performance of, learned motor responses.

Key words: striatum; electrophysiology; S-R habit; chronic recording; dopamine; movement
The lateral striatum contains a population of neurons that discharge spontaneously at low rates and phasically in relation to sensorimotor activity of individual body parts. Their functional organization is in register with convergent, patchy somatotopic projections from primary somatosensory and motor cortices (Kunzle, 1975, 1977; Liles, 1979; Crutcher and DeLong, 1984; Alexander and DeLong, 1985; Liles and Updyke, 1985; McGeorge and Faull, 1989; Kimura, 1990; Carelli and West, 1991; Flaherty and Graybiel, 1993). They are projection neurons (Kimura et al., 1990), the main targets of striatal output being the globus pallidus and substantia nigra pars reticulata. The organization of corticostriatal-pallidal connections has led to the suggestion that the distributed representation of body parts of the striatum may allow associative processing involved in sensorimotor learning (Flaherty and Graybiel, 1994).

Neurons related specifically to the forelimb are the best characterized subpopulation of phasic neurons. Although clearly "movement-related," their properties indicate certain dissociations from movement. Firing of most neurons (type IIb of Kimura, 1990) lags behind the onset of electromyogram (EMG) activity of arm muscles (Crutcher and DeLong, 1984b; Liles, 1985; Kimura, $1990)$, so that any major role in movement initiation is unlikely. The parameter most frequently correlated with firing is the direction of movement, but in half the cases, firing shows no relation to load (Crutcher and DeLong, 1984b; Liles, 1985; Alexander, 1987). Firing also occurs during passive movement and cutaneous stim-

Received Aug. 8, 1996; revised Dec. 11, 1996; accepted Dec. 13, 1996.

This work was supported by National Science Foundation Grant BNS-8708523, National Institute on Drug Abuse Grant DA 04551, and the Charles and Johanna Busch Memorial Fund. We thank Drs. Laura Peoples, Charles Flaherty, Tim Otto, and Louis Matzel for discussions of this project; Patrick Grace for technical assistance; and Linda King for help with histology.

Correspondence should be addressed to Dr. R. M. Carelli, Department of Physiology and Pharmacology, Bowman Gray School of Medicine, Medical Center Boulevard, Winston-Salem, NC 27157.

Dr. Wolske's present address: Prairienet, Graduate School of Library and Information Science, University of Illinois, Champaign, IL 61820.

Copyright (C) 1997 Society for Neuroscience $\quad 0270-6474 / 97 / 171804-11 \$ 05.00 / 0$ ulation (Crutcher and DeLong, 1984a; Liles, 1985; West et al., 1990; Carelli and West, 1991). These properties suggest a role in integrating signals involved in ongoing movement, such as somatosensory feedback and/or efference copy, transmitted via the corticostriatal system (Kato and Kimura, 1992).

Most of this information has been obtained from trained animals, but training itself influences the responsiveness of neurons in the striatum and substantia nigra. Responses of dopamine (DA) neurons to reward were transferred to a conditioned stimulus (CS) predictive of reward in a simple stimulus-response (S-R) task (Romo and Schultz, 1990; Ljungberg et al., 1992; Mirenowicz and Schultz, 1994), but declined with overtraining as the behavior became automatic (Ljungberg et al., 1992; Schultz, 1993). Tonically active neurons (TANs), a striatal category separate from the slowly discharging, phasic category, developed responsiveness to a CS as a function of acquisition of a sensorimotor association. After overtraining, TANs maintained this responsiveness, in contrast to the decline with overtraining expected of DA neurons, suggesting a possible transfer of information to TANs for storage and use in conditioned motor behavior (Aosaki et al., 1994).

Further suggesting a striatal role in learning, the corticostriatal system is implicated in motor learning and the formation of habits (Marsden, 1982; Mishkin and Petri, 1984; Squire et al., 1993). Acquisition of these forms of nondeclarative memory is impaired after damage to the striatum but characteristically is spared after limbic lesions (Olmstead et al., 1976; Siegfried and Bures, 1980; Martone et al., 1984; Sabol et al., 1985; Whishaw et al., 1986; Heindel et al., 1988, 1991; Phillips et al., 1988; Pisa, 1988; SaintCyr et al., 1988; Knopman and Nissen, 1991; McDonald and White, 1993). These data and reports of nigrostriatal changes as behavior becomes automatic encourage further study of striatal activity during motor learning. In an initial study (Carelli and West, 1991b), firing of striatal forelimb neurons during cued lever pressing was time-locked to the lever press during early sessions but not after repeated sessions, suggesting a change as a function of learning. Our objective here was to examine more rigorously 
this change in relation to variables that might also change across sessions, such as cue discrimination, timing and form of the movement, and the ability to sample reliably from the same population.

\section{MATERIALS AND METHODS}

\section{Subjects}

Long-Evans male rats (Charles River Laboratories, Wilmington, MA), 90- to 120-d-old, were used as subjects. Animals were maintained on a reversed light/dark cycle (on 20:00, off 08:00) so that experiments were conducted during their active period.

\section{Electrophysiological recording}

Before they were trained, animals were surgically prepared for chronic single-unit recording by implantation of a base for attaching a miniature microelectrode drive (microdrive) assembly (Josef Biela Engineering, Anaheim, CA) over the left striatum (medial-lateral 3.6 or $4.0 \mathrm{~mm}$, anterior-posterior $+0.80 \mathrm{~mm}$ relative to bregma, level skull). Details of the microdrive and surgical procedure have been reported elsewhere (Deadwyler et al., 1979; West and Woodward, 1984). Animals were also prepared for chronic EMG recording in the biceps or triceps muscles of the right forelimb and/or the deltoid muscle of the right shoulder. Two flexible, stainless steel wires (7-stranded, Teflon-coated, $125 \mu \mathrm{m}$ diameter) (A-M Systems, Inc.) were twisted together for differential recording. The wires were intertwined around a $5 \times 5 \mathrm{~mm}$ piece of Teflon mesh (USCI, a Division of C. R. Bard, Inc.) with the tips extending $4 \mathrm{~mm}$ beyond the end of the mesh. The wire tips were stripped of their insulation ( $0.5 \mathrm{~mm}$ length) and arranged into a "V" formation to enable easy insertion into the muscle as well as to provide resistance from being pulled out of the muscle. The wires were routed subcutaneously until the Teflon mesh overlay the muscle, which was gently pushed apart by blunt dissection. The recording wires were inserted into the muscle and secured by suturing both ends of the mesh into muscle. The other end of the bipolar wire was led subcutaneously and finally led through syringe elasticon (Kerr, Inc.) to a connector in the recording headstage attached to the skull. Animals were housed individually and had free access to food (Purina lab chow) and water. After they reattained presurgical body weight, animals were deprived of water and maintained at $82 \%$ of that weight.

Recording sessions began at least 1 week after surgery. Each day, the microdrive was equipped with a tungsten microelectrode $(10 \mathrm{M} \Omega$, Haer Corp., Brunswick, ME) and attached to the base on the skull of the animal. As the recording electrode was lowered into the striatum, identification of forelimb-related firing was accomplished by a sensorimotor examination of firing during active movement, passive manipulation, and cutaneous stimulation of the forelimb, as detailed previously (West et al., 1990; Carelli and West, 1992). The exam was conducted before the start of each experimental session in the same experimental chamber in which the task was subsequently conducted, with a black plexiglas wall blocking access to the lever and water trough. Only right (contralateral) forelimbrelated neurons were studied during lever pressing in the task.

Neuronal signals were amplified and led through a bandpass filter (500-10,000 Hz). EMG signals were led through a Grass Dual P9 AC Differential Preamplifier and bandpass filter $(350-5000 \mathrm{~Hz})$. An AST Premium 386 computer using the Datawave Systems Discovery neurophysiology package (DataWave Systems, Inc., Boulder, CO) was used to simultaneously record single-unit activity from the striatum and EMG activity, and control behavioral aspects of the experiment, as well as for off-line waveform discrimination and construction of perievent histograms (PEHs). Multiunit muscle potentials were analyzed for the purpose of identifying the onset of movements (Ghez and Vicario, 1978; Kimura, 1990) using visual inspection of PEHs. EMG amplitude was not quantified and varied from session to session, most likely a result of slight spontaneous shifts in the location of the subcutaneous wire relative to the muscle.

\section{Experimental chamber}

Sessions were conducted in a clear plexiglas chamber (length, $32 \mathrm{~cm}$; width, $17 \mathrm{~cm}$; height, $40 \mathrm{~cm}$ ) mounted above a treadmill (Sears belt sander model 113.22590). The treadmill belt served as the floor of the chamber and was coated with a thin layer of silicone gasket material (General Electric model 343). One wall of the chamber contained a separate, moveable, clear plexiglas wall with a rectangular opening $(3.5 \times$
$2.5 \mathrm{~cm}$ ), which exposed an operant lever mounted $4 \mathrm{~cm}$ from the floor. The wall was hinged to the ceiling of the chamber, enabling it to be moved backward or forward, thereby resulting in complete exposure or retraction of the lever, respectively.

The lever was calibrated to function as a force lever, as follows. The amount of lever depression (downward movement) determined the extent to which the lever interrupted a photocell beam behind it. The extent of interruption was converted using a transistor circuit into five successive "bins" corresponding to five increments in force applied to the lever. Separate inputs to the computer corresponded to initiation of the press, 1-5 gm (bin 1); 6-10 gm (bin 2); 11-15 gm (bin 3); 16-20 gm (bin 4); $21-25 \mathrm{gm}$ (bin 5). Depression to any numbered bin necessarily was preceded by transition through lower numbered bins. Lever depression was accompanied by analog changes in distance and applied force, but transitions between bins were transparent to the subject. Force for each bin was calibrated daily by adjusting the tension in a thin metal band contacted by the far side of the lever. Force, rather than distance, was the programmed variable (described below). Distance was not quantified, but approximated $1 \mathrm{~cm}$ vertically in a maximal depression, averaging $\sim 2 \mathrm{~mm}$ per bin. Water $(0.05 \mathrm{ml})$ was delivered by activation of a solenoid device (General Valve Co.) into a water trough located $6 \mathrm{~cm}$ to the left of the lever and $3 \mathrm{~cm}$ from the floor.

\section{Behavioral task}

Animals initially were trained to press the lever on a continuous reinforcement schedule. The lever was gradually retracted and animals were required to reach through the small hole in the wall of the chamber with the right forepaw to lever press. The reach covered $\sim 4 \mathrm{~cm}$ vertically and $1.5 \mathrm{~cm}$ anteriorly. The lever then remained retracted $(5 \mathrm{~mm}$ behind the wall), and both neural recording and the tone were introduced in session 1. As illustrated in Figure 1, rats were trained to stand facing the lever, before the beginning of each trial, with the right forepaw on a piece of white tape $(2.5 \times 4.0 \mathrm{~cm})$ situated flat on the floor $1.5 \mathrm{~cm}$ in front of the lever. Placement of the forepaw of the animal on (or within $5 \mathrm{~mm}$ of) the tape for $0.5-1.0 \mathrm{sec}$ was required before the experimenter activated the tone $(1 \mathrm{kHz}, 65 \mathrm{~dB})$. The tone was initiated by the experimenter to ensure a consistent starting position that approximated a resting posture of the forelimb on the floor. This was preferred over an automated initiation of the tone, e.g., by requiring depression of a second lever, because that would have confounded the present design. Water delivery was contingent on lifting the forepaw from the tape and pressing the lever within 7 $\mathrm{sec}$ of tone onset, to a minimum force of $11 \mathrm{gm}$ (entry into bin 3 ), which terminated the tone. Lever presses in the absence of the tone were not reinforced. The next trial began with the next placement of the right forepaw of the animal on the white tape. An experimental session consisted of 70 presentations of the tone ( 70 trials; one session per day for at least 18 consecutive days).

\section{Behavioral measures}

"Response to tone" was defined as the percentage of total trials per session in which the animal lever pressed during the tone. "Intertrial interval (ITI) lever press" was defined as the percentage of total ITIs per session during which the animal lever-pressed (without reinforcement) one or more times. "Reaction time" (RT), the time from tone onset to the reinforced lever press, was divided into three nonoverlapping components (Fig. 1). The first component, "tone onset to biceps/deltoid EMG onset" (termed $\mathrm{RT}_{1}[$ tone-EMG]), was interpreted as a reflection of learning to respond during the tone. The second component, "biceps/ deltoid EMG onset to lever press" (termed $\mathrm{RT}_{2}$ [EMG-press]), was the time from EMG onset to the onset of the reinforced lever press (i.e., the time period during which the animal lifted the paw, reached toward the lever, and entered bin 1 thereby initiating the lever press). The third component, "lever press onset to reinforcement" (termed $\mathrm{RT}_{3}$ [pressreinforcement]), was the time from the initiation of lever depression (bin 1 entry) to entry into bin $3 . \mathrm{RT}_{2}$ and $\mathrm{RT}_{3}$ were interpreted as reflecting motoric performance of the response.

\section{Data analysis}

PEHs were constructed to determine relationships among forelimbrelated neuronal activity, EMG activity, and behavioral events. Events included the reinforced lever press (bin 3 entry) and tone onset during the task, and cutaneous stimulation or passive manipulation of the limb during the exam. Simultaneously with each cutaneous stimulus or passive manipulation, the experimenter pressed a computer key as an approxi- 


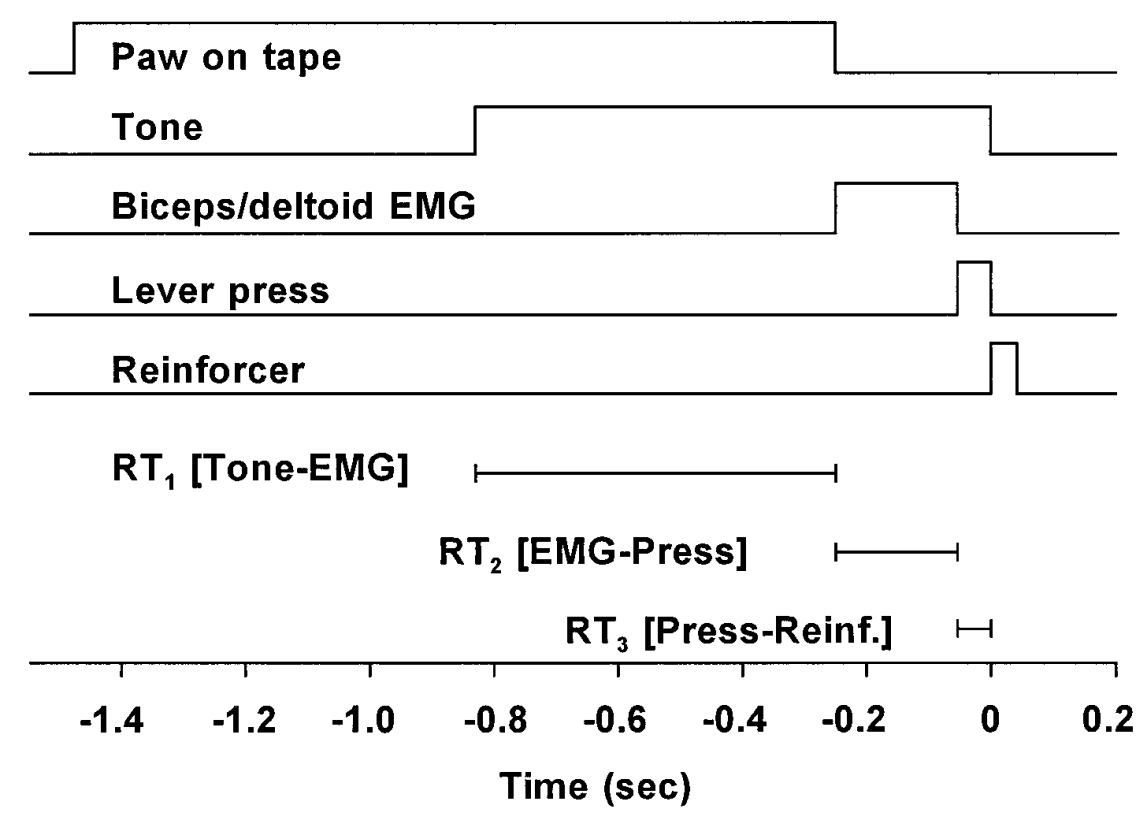

Figure 1. Schematic diagram of behavioral task and RT measures. Animals were trained to place the contralateral forepaw on a piece of tape on the floor, situated directly in front of the lever. Correct forepaw placement for $0.50-1.0 \mathrm{sec}$ activated a tone, during which the animal lifted its forepaw from the tape (activation of biceps/deltoid EMG), and pressed the lever activating water delivery. See text for description of RT measures. Times are approximate means across animals and represent behavior of a trained animal. Time $0=$ entry of lever into bin 3 (11 $g$ force).

\section{RESULTS \\ Preliminary examination}

Seven hundred fourteen striatal neurons were recorded in the dorsolateral striatum of three rats. Of these, 210 cells $(29 \%)$ were related to whole-body movement, 197 cells (28\%) were unresponsive, and 307 cells $(43 \%)$ were related to sensorimotor activity of individual body parts. Of the latter category, 86 neurons were related specifically to the right (contralateral) forelimb, and 53 of these were recorded during the lever-pressing task. During the exam, all 53 forelimb neurons increased firing during active movement. Of the 53 neurons, 31 increased firing during cutaneous stimulation of the contralateral forelimb, 32 increased firing during passive manipulation of the forelimb, and 20 responded to both.

\section{Behavior during the task \\ General description}

Each session began with a click of the solenoid, removal of the black blocking wall, and exposure of the lever and water trough. Animals immediately approached the trough and drank the water. After the animal drank, the body of the animal was positioned between the trough and the lever, oriented and positioned to touch the floor tape, press the lever, and drink the water. Once in this position, the animal either lever-pressed (i.e., ITI error) or placed the forepaw on or near the floor tape. The latter resulted in presentation of the tone, during which a lever press was reinforced. After the click of the solenoid, the forepaw was removed from the lever, and the upper body was maneuvered to drink the water, as described above. Minimal postural adjustments were involved, consisting mainly of maneuvering the upper body between the lever and the trough.

\section{Behavioral measures}

Task requirements restricted variation in the forelimb movement involved in the lever press, and experimenter observation confirmed that reaching from the floor to press the lever remained similar in form throughout all sessions. Figure 2 (middle and bottom right) shows that no significant changes as a function of session number were observed for any animal in $\mathrm{RT}_{2}\left[\mathrm{EMG}-\right.$ press] or in $\mathrm{RT}_{3}$ [press-reinforcement]. Because the wire placement within the biceps, triceps, or deltoid muscles. Muscle anatomy was verified according to Greene (1963). 

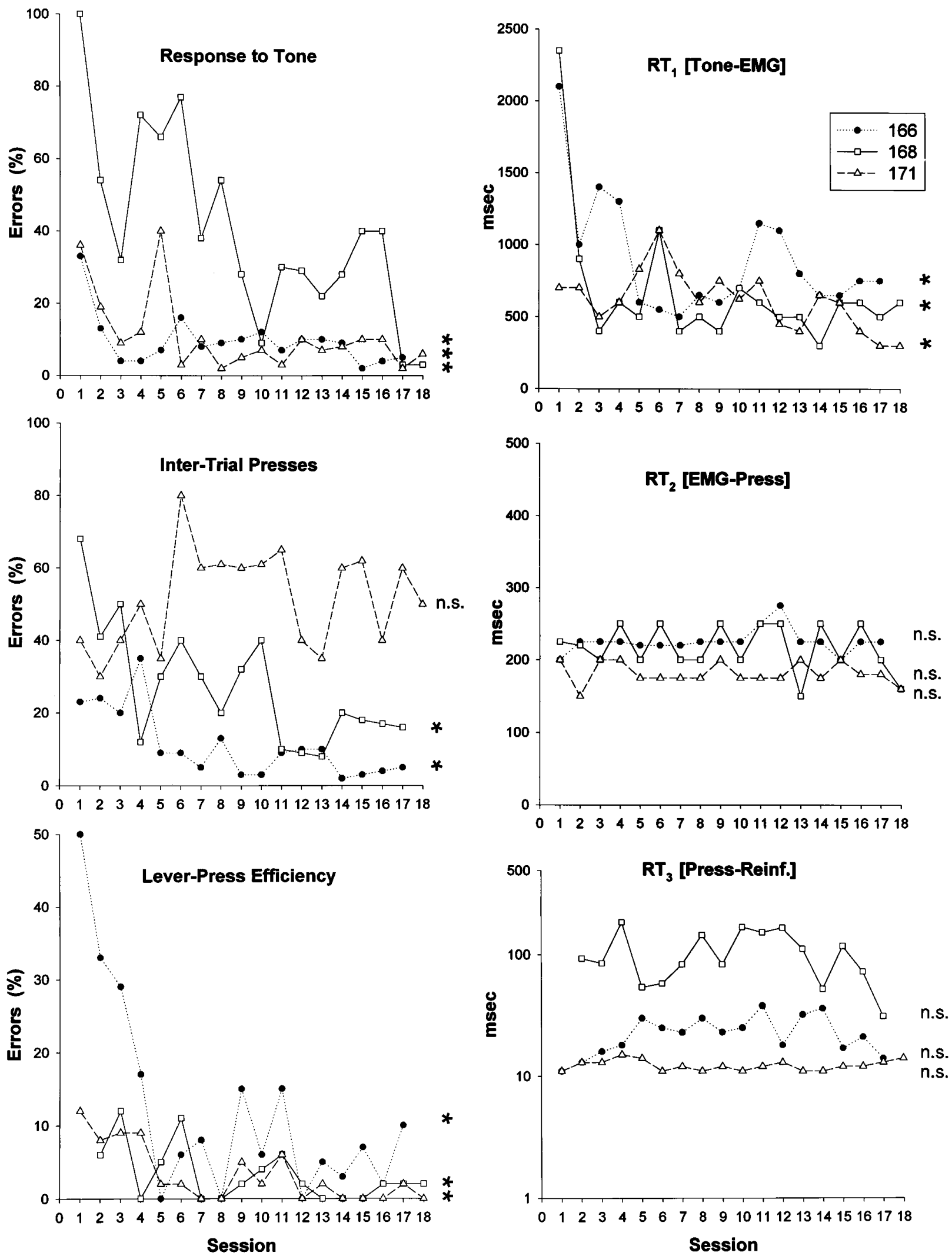

Figure 2. Left column, Percentage of trials in each session in which the animal responded during the tone, i.e., completed a reinforced lever press (top); completed one or more (unreinforced) lever presses during the ITI (middle); or pressed the lever beyond the force required for water delivery (bottom). Right column, RT measures (msec). $R T_{1}=$ time from onset of tone until onset of biceps or deltoid EMG activity. $R T_{2}=$ time from onset of biceps or deltoid EMG activity until onset of lever press. $R T_{3}=$ time from onset of lever press until lever depression to the force required for water delivery. Asterisk indicates significant $(p<0.01)$ change as a function of session number (n.s., not significant). 
NEURONS BICEPS TRICEPS

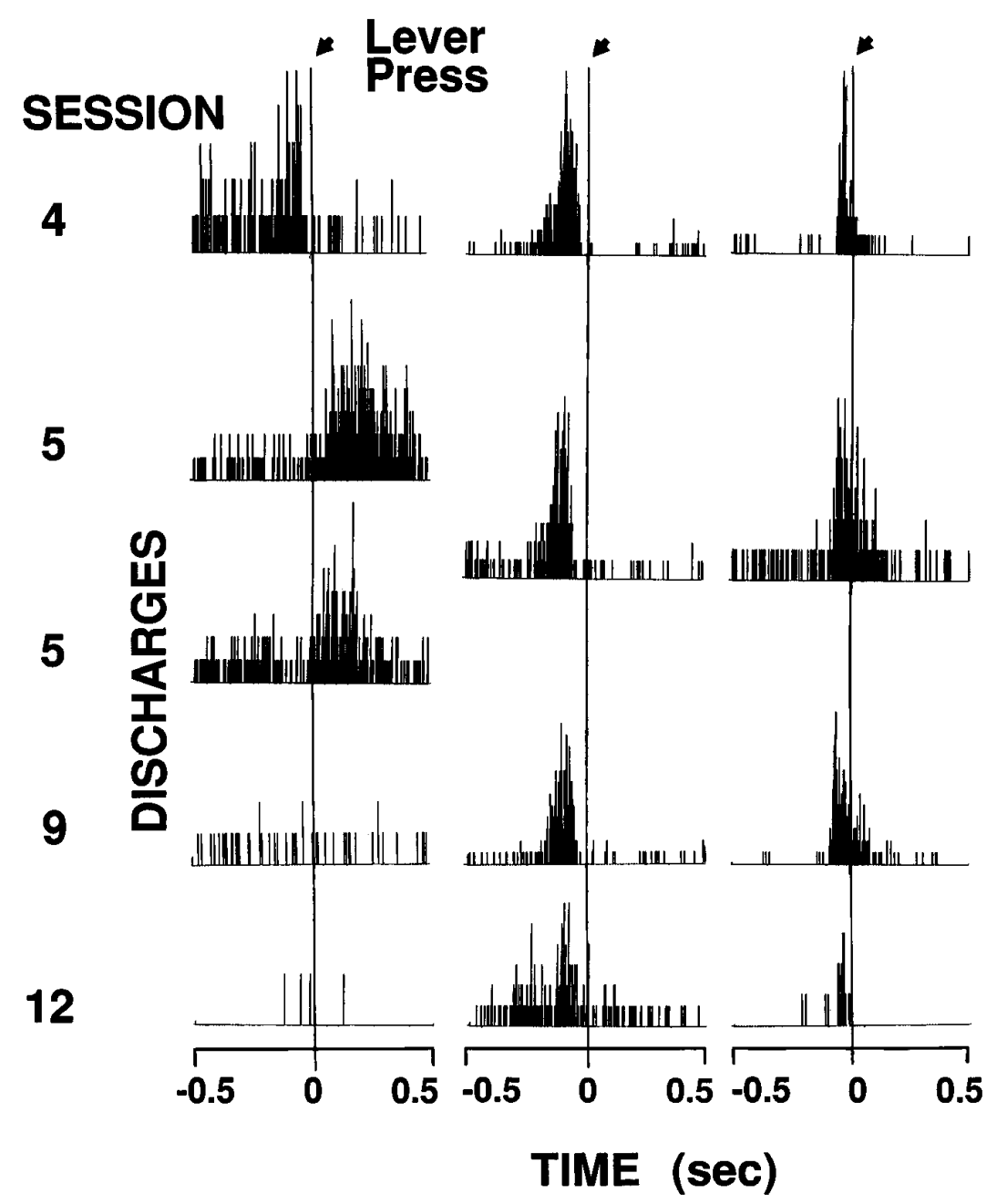

FORELIMB STIM.

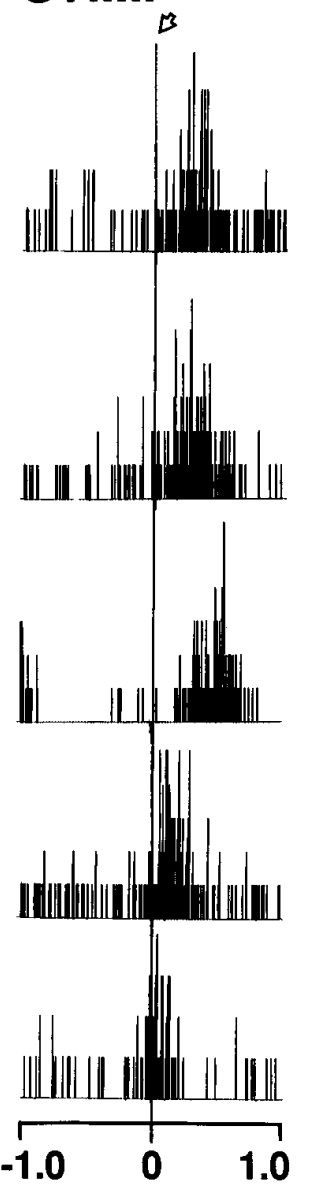

Figure 3. Decline in lever press-related firing of striatal forelimb neurons after repeated sessions. Three left vertical columns, PEHs display activity of forelimb neurons and simultaneously recorded biceps and triceps EMG activity across representative sessions for one animal (166). Reinforced lever press is "node" (bin 3 entry, time 0), indicated by solid vertical lines and filled arrows (70 trials in each). Neuronal activity was time-locked to lever press during acquisition (e.g., sessions 4 and 5, the latter yielding neurons) but not after repeated sessions (e.g., 9 and 12). Timing of onset of biceps/triceps EMG activity remained similar across sessions (amplitude was not quantified; $2 \mathrm{msec} / \mathrm{bin}$ ). Vertical column to right of dashed line, PEHs show responsiveness of each neuron at far left to cutaneous stimulation during exam before session (60 repetitions of tapping or rubbing limb/paw, indicated by solid vertical line and open arrow; $4 \mathrm{msec} / \mathrm{bin})$.

distances associated with $\mathrm{RT}_{2}$ (floor to lever) or $\mathrm{RT}_{3}$ (distance the lever travelled to enter bin 3 ) did not change, it can be concluded that no change as a function of session number occurred in the average velocity of either the reach or the press.

PEHs showing activity recorded from prime movers of the forelimb were constructed using the reinforced lever press (bin 3 entry) as the node (time 0, Figs. 3 and 4). Biceps and deltoid EMG activity increased as the animal lifted the paw to reach for the lever, then decreased to baseline during lever depression. Triceps EMG activity remained at baseline until it increased during lever depression, beginning $\sim 50 \mathrm{msec}$ before completion of the reinforced lever press, and returned to baseline when the animal withdrew the forepaw from the lever. Only slight variations in the timing of EMG activity relative to the reinforced lever press were observed across all sessions and animals: biceps mean onset $=$ $-177 \pm 5 \mathrm{msec}$, mean duration $=156 \pm 7 \mathrm{msec}$; deltoid mean onset $=-155 \pm 5 \mathrm{msec}$, mean duration $=125 \pm 5 \mathrm{msec}$; triceps mean onset $=-43 \pm 9 \mathrm{msec}$, mean duration $=49 \pm 13 \mathrm{msec}$. This low variance and the lack of change in $\mathrm{RT}_{2}$ or $\mathrm{RT}_{3}$ (Fig. 2) indicate that animals did not alter the timing of the reach and the press across sessions.

All three animals showed significant improvement in measures of tone discrimination as a function of repeated sessions on the task (Fig. 2). As session number increased, animals made fewer errors of omission (failure to respond to the tone) and commission (ITI presses; with one exception: rat 171), and responded to the tone with shorter RTs $\left(\mathrm{RT}_{1}\right.$, tone onset to EMG onset).

All three animals also showed significant improvement in the efficiency of the lever press as session number increased. Figure 2 (lower left) shows a reduction in the percentage of trials containing "errors," which consisted of superfluous fluctuations of the lever beyond the force requirement, after bin 3 entry/water delivery. 


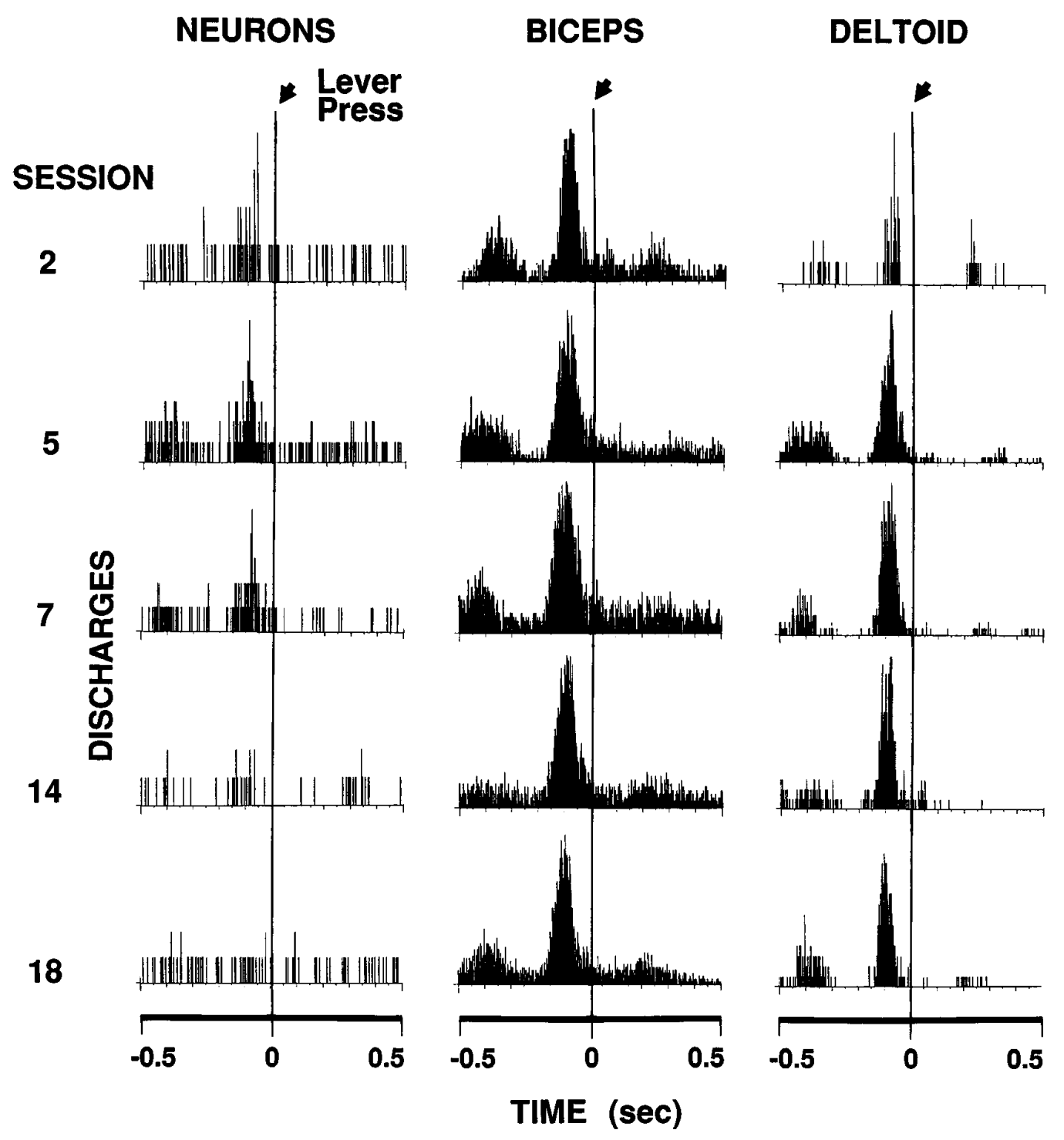

Figure 4. Decline in lever press-related firing of forelimb neurons after repeated sessions in a different animal (171). Firing was time-locked to the reach toward lever during acquisition (e.g., sessions 2, 5, and 7) but not after repeated sessions (e.g., 14 and 18). Onset of biceps/deltoid EMG activity was similar across sessions. Secondary peaks in neuronal activity and EMG activity at $-0.50 \mathrm{sec}$ reflect residual from ITI lever presses, which persisted at three to four per ITI for this animal. Details as in Figure 3, left.

\section{Disappearance of firing related to the lever press after repeated sessions on the task}

The main finding of this study was that forelimb neurons fired in relation to the lever press during early sessions, but did not do so after repeated sessions on the task. This was true even though all neurons were verified by the exam to fire in relation to active movement specifically of the forelimb, as well as to passive manipulation and/or cutaneous stimulation for some neurons (e.g., Fig. 3, right column). Examples of activity recorded from single forelimb neurons and simultaneously recorded EMG activity are illustrated in PEHs for representative sessions of two animals in Figures 3 and 4. One forelimb neuron (Fig. 3, session 4) exhibited an increase in firing rate during the reach toward the lever, whereas two others (session 5) recorded simultaneously increased firing after the onset of lever depression; however, after repeated sessions on the task (e.g., sessions 9 and 12), no such activity related to the lever press was observed. A similar pattern is shown for another animal in Figure 4. Increased firing rate related to reaching toward the lever was observed in early sessions (e.g., sessions 2, 5, and 7), and an absence of firing related to the lever press was observed in late sessions (e.g., sessions 14 and 18).

A graphic summary of these changes is presented in Figure 5, in which $\mathrm{S}: \mathrm{B}$ for each of the 53 forelimb neurons is plotted as a function of session number for each animal. Although some values $<1.5$ were observed in early sessions, most forelimb neurons recorded in the first few sessions showed severalfold increases in firing rate as the forelimb moved from its position on the floor to reach for and press the lever. Such increases were not observed for any forelimb neuron recorded in the later sessions. This pattern showed a striking consistency in every animal tested; in all three cases, $\mathrm{S}: \mathrm{B}$ showed a significant $(p<0.01)$ decrease with increasing session number.

Of 53 forelimb neurons recorded from all three animals during the task, 21 showed firing time-locked to the lever press (S:B > $1.5)$. For these 21 neurons, the firing rate associated with reaching toward (14 neurons) or pressing (7 neurons) the lever, i.e., signal, 

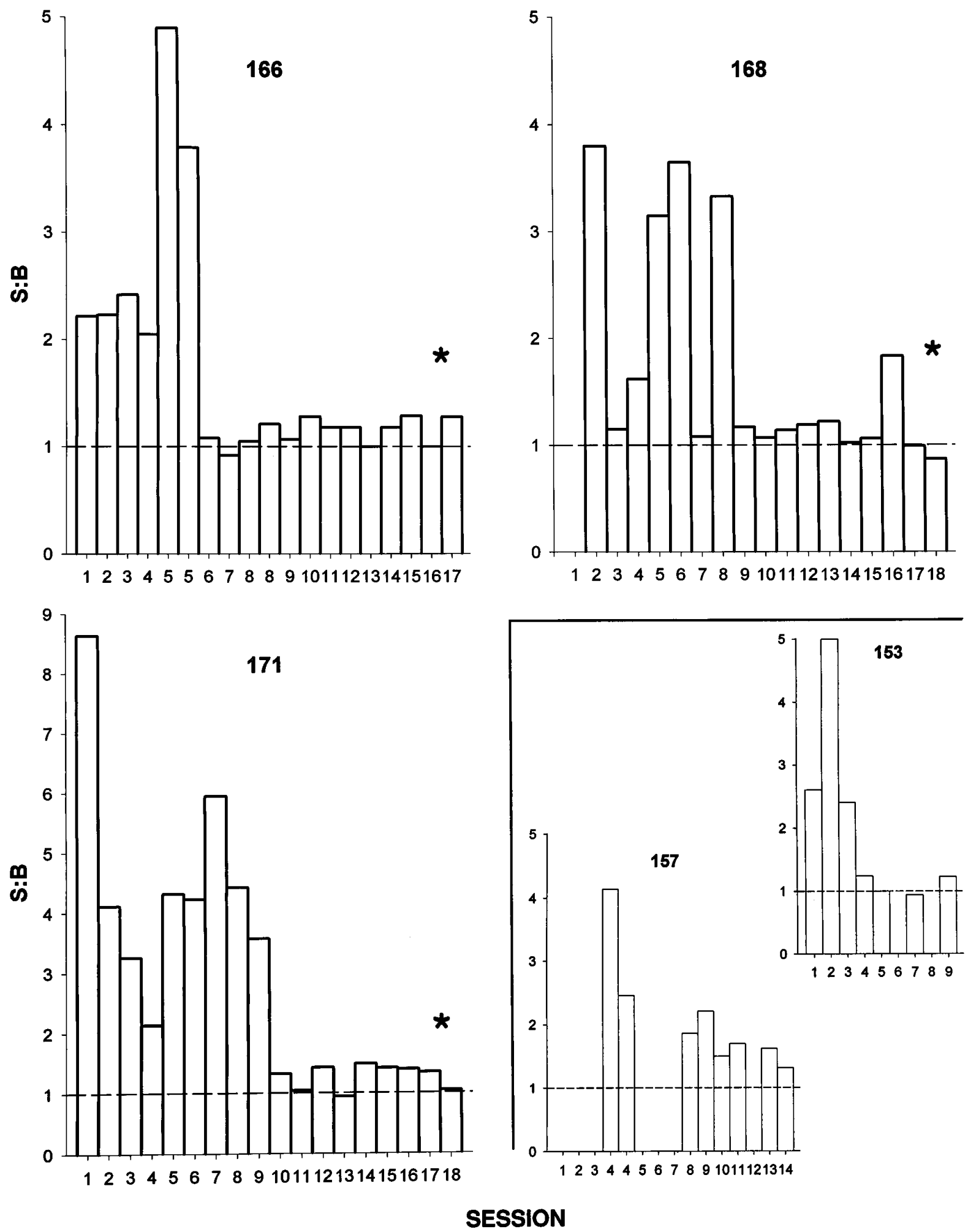

Figure 5. S:B across all sessions for each animal (animal number at top). Each vertical bar represents S:B for one forelimb neuron. Ratio near 1 (dashed horizontal line) indicates that firing rate did not change as the paw moved from position on tape to reach and press the lever. Asterisk indicates significant $(p<0.01)$ change in S:B as a function of session number. Inset, Similar trend in S:B as a function of session number obtained from two animals in the initial study.

was as much as 9 times greater than that during baseline, when the paw was stationary on the floor. Of the 21 neurons showing time-locked firing, all except one were recorded early in training, i.e., sessions $1-9$, representing $71 \%$ of the 28 neurons recorded in those sessions. Only one neuron that showed time-locked firing $(\mathrm{S}: \mathrm{B}=1.8)$ was recorded after session 9 , constituting $4 \%$ of the 25 neurons recorded in late sessions (10-18).

It was not possible to track the activity of the same neuron for 
18 sessions, but the data lead to the conclusion that the activity of the population of forelimb neurons changed as a function of session number. An alternative is that forelimb neurons might belong to separate subpopulations (indistinguishable in the exam): "time-locked" and "non-time-locked" to the lever press, the latter sampled mainly in late sessions. Accordingly, our differential of 20 time-locked neurons (early) to one time-locked neuron (late) occurred by random sampling from the two hypothetical subpopulations. Because 28 total neurons (early) and 25 total neurons (late) were sampled, the probability (relative frequency) of sampling any given neuron early versus late is 28 of 53 (0.528) and 25 of $53(0.472)$, respectively. The probability of obtaining the observed differential of 20:1 for time-locked neurons by random sampling is $0.528^{20} \times 0.472^{1} \times 21=0.00003$, effectively eliminating this alternative.

Neural data are included for the two animals from the initial study (Carelli and West, 1991b), in which the full complement of neural and behavioral data were not collected. Both animals exhibited a decrease in S:B as session number increased (Fig. 5, inset). Available behavioral data (response to tone, and total RT only) showed that both animals also evidenced acquisition of tone discrimination. One showed $43 \%$ errors in responding to the tone in session 1, which improved to asymptotic values of $7 \%, 3 \%$, and $2 \%$ in sessions 7,8 , and 9 . Total RTs similarly improved from 0.74 sec to $0.43,0.66$, and $0.65 \mathrm{sec}$ in those same sessions. The second animal improved from $35 \%$ errors in responding to the tone in session 4 to $22 \%$ in session 14 ; total RT improved from 2.6 to 1.7 sec in those sessions.

\section{Lack of short-latency tone-evoked neuronal responses}

Comparison of firing between the periods -100 msec versus +100 msec relative to tone onset was not confounded by forelimb movement because (1) the preceding $100 \mathrm{msec}$ corresponded to stationary forelimb position on the floor and (2) forelimb movement did not begin for at least $300 \mathrm{msec}$ after tone onset $\left(\mathrm{RT}_{1}\right.$ in Fig. 2, top right). Of the 53 forelimb neurons, only one showed tone-evoked activity (inhibition; rat 168, session 3 ). No toneevoked activity was observed for any forelimb neuron during the late sessions, i.e., after acquisition of tone discrimination.

\section{Histology}

Reconstruction of three-dimensional locations of electrode tips (Carelli and West, 1991) revealed that all forelimb neurons were located in the forelimb region of the dorsolateral striatum $(+0.20$ to $+1.6 \mathrm{~mm}$ anteroposterior) (compare West et al., 1990, and Cho and West, 1997). Dissection of the right forelimb and the right shoulder of each animal revealed that in all instances muscle formed around the Teflon mesh used to secure the EMG wires in place. The EMG wires were located underneath the mesh, within the triceps or biceps muscles of the right forelimb, or the deltoid muscles of the right shoulder.

\section{DISCUSSION}

An initial study (Carelli and West, 1991b) had shown that the firing of striatal forelimb neurons during lever pressing declined after animals learned to lever press. Therefore, the most important aspect of the present design was to eliminate variability from the task and from daily protocols that could potentially account for such changes in firing. Animals were required simply to press a lever from a particular starting point in response to a tone cue. This contingency remained the same on every trial and every session. In early sessions, the majority of forelimb neurons fired in relation to the lever press, as expected; however, after repeated daily sessions, striatal neurons related to movement of the forelimb no longer fired in relation to virtually the same movement to which firing had been time-locked during early sessions.

The change in firing could have been related to one or more of the behavioral variables that changed across sessions. No changes were observed in forelimb movement involved in reaching and pressing the lever to the level required for reinforcement. Nonetheless, all three animals improved in the efficiency of lever pressing, measured as fewer extraneous fluctuations beyond that level of force. This effectively reduced force and distance by 5-10 gm and 2-4 $\mathrm{mm}$ in later sessions; however, it is not likely that these reductions explain the elimination of firing time-locked to the lever press. The most compelling reason is that any such contribution could not have applied to the majority of neurons studied. An estimated two-thirds of all neurons were related to the reach toward, not the depression of, the lever (estimated on the basis of the $2: 1$ ratio of the former to the latter). Therefore, declining force or distance could have contributed to the decline in S:B for only an estimated one-third of the neurons studied. Second, firing rates of load-related or distance-related striatal forelimb neurons are reduced, not eliminated by, reductions in force (Crutcher and DeLong, 1984b; Liles, 1985) or distance (Kimura, 1990) of forelimb movement. Thus, the observed partial reductions in force and distance as a function of session number do not explain the absence of time-locked firing in later sessions. Furthermore, $\sim 50 \%$ of striatal forelimb neurons are load-related (Crutcher and DeLong, 1984; Liles, 1985). This leaves only 50\% of the estimated one-third of our sample (i.e., the neurons related to depression of the lever) in question, further restricting any explanatory power of this argument. Therefore, it is reasonable to conclude that with increasing session number the gradual disappearance of firing in relation to the lever press (1) occurred despite the similarity of numerous movement parameters across sessions and (2) cannot be accounted for satisfactorily by the partial reduction in force or distance exhibited in later sessions.

Instead, the gradual reduction in superfluous fluctuations beyond the required level of lever depression may be viewed more appropriately as an improvement in efficiency or accuracy, concomitant with acquisition of skill in the task. These fluctuations appear to be analogous to final "current control," i.e., small, oscillating corrections made before the end of a movement to a target. Such fluctuations predominate early in learning a movement but tend to be eliminated as a function of experience, as ballistic movements become more acurate and/or predominant (Brooks, 1979) (see below).

Acquisition was demonstrated further by changes in other key behavioral measures that were not measures of the movement per se. All animals exhibited tone discrimination, by (1) reducing the percentage of tone presentations to which animals failed to respond, and (2) reducing $\mathrm{RT}_{1}$, time to initiate forelimb movement in response to tone onset. Two animals also reduced the number of lever presses made in the absence of the tone, whereas one did not. With that single exception, the topography of each measure (response to tone, $\mathrm{RT}_{1}$, intertrial presses, and efficiency) as a function of session number was curvilinear, exhibiting a negative acceleration and approximate asymptote. These topographies conform to exponential models of learning and demonstrate acquisition of what has been termed a lever-pressing habit (Hull, 1943; Estes, 1959; Spence, 1960).

The acquisition of a habit involves the gradual development of specific S-R bonds (Mishkin et al., 1984; Squire et al., 1993). A 
habit is distinguished by the tendency to be "response-like" in that it is triggered automatically by a particular stimulus or stimulus complex (Dickinson, 1985). Furthermore, acquisition of a skilled movement involves a progression from movements requiring current control and feedback, to ballistic movements that are made correctly with less current control and are uninfluenced by peripheral feedback (Polit and Bizzi, 1978; Moroz and Bures, 1983; Zhuravin and Bures, 1986; Saling et al., 1992; Hocherman, 1993; for reviews, see Keele, 1968; Brooks, 1979; Cooke, 1980). The striatum has been suggested to play a role in the acquisition of habits and certain motor skills (Marsden, 1982; Mishkin et al., 1984). Parkinson's patients have been described as "having lost the advantages of working ballistically, notably those of increased speed and reduced information load in the sensory-motor system" (Flowers, 1975).

If the striatum and its DA input are necessary for the acquisition of motor skills and/or habits, then activity of neurons in the nigrostriatal system ought to show correlations with their acquisition. Such correlations have indeed been found, specifically with respect to neuronal responses to conditioned stimuli after overtraining (Ljungberg et al., 1992; Schultz, 1993; Aosaki et al., 1994). The present report is the first, to our knowledge, to demonstrate a disappearance of movement-related firing of striatal neurons as a function of acquisition.

Initially, DA may be necessary for processing by striatal forelimb neurons of lever press-related sensorimotor information projected to them via the corticostriatal system. In turn, their activity may be necessary to their targets in premotor areas for developing computations that will be used subsequently, by neural networks controlling the lever press after it has become (in various terminologies) automatic, preprogrammed, or S-R habit. As the processing of sensorimotor variables is eliminated, striatal forelimb neurons may participate less in the lever press, provided conditions remain constant. This decline in sensorimotor processing is in line with the proposed decline in processing of conditioned stimuli as a function of learning (Pearce and Hall, 1980). Our interpretation is also consistent with the suggestion that computations for executing certain learned movement sequences may be performed outside the striatum (Marsden, 1982). That the striatum may participate, in certain instances, in the acquisition of motor skills whose computations are stored elsewhere is analogous to the conceived role of the medial temporal/diencephalic memory system in the initial stages of forming permanent declarative memories, which are ultimately stored elsewhere (Milner, 1970; Squire, 1993).

Other studies have shown a continued presence of task-related striatal activity after extensive training (e.g., Crutcher and DeLong, 1984b; Liles, 1985; Alexander and Crutcher, 1990a,b; Crutcher and Alexander, 1990; Gardiner and Nelson, 1992; Kimura et al., 1992; Jaeger et al., 1993). Those tasks continued to engage the activity of striatal neurons, presumably because they required processing of complex sensorimotor variables (Alexander et al., 1992) that changed unpredictably from trial to trial. The tasks lacked the simple, repetitive contingency held constant on every trial of every session in our task, in which the single stimulus was programmed to provide no information other than a temporal reference for the single response. Indeed, after primates were overtrained in a task similar to the present task, responses of DA neurons to the CS were reduced considerably (Ljungberg et al., 1992), which was interpreted as a potential influence on striatal processing involved in the acquisition of habits.

Only 1 of 53 forelimb neurons exhibited a short latency response to the tone $\mathrm{S}^{\mathrm{D}}$, consistent with previous studies (Crutcher and DeLong, 1984; Kimura et al., 1984; Alexander, 1987). In this respect, the present sample resembles type IIb neurons (Kimura, 1990). Discharges initiated by a conditioned stimulus (West et al., 1987; Schultz and Romo, 1988) are characteristic of other functionally defined populations of striatal neurons, such as type IIa (Kimura, 1986; 1990; Gardiner and Nelson, 1992; Romo et al., 1992) and TANs (Kimura et al., 1984; Apicella et al., 1991; Aosaki et al., 1994).

Each neuron recorded in each of 18 sessions was verified in the preliminary sensorimotor exam to be responsive specifically during active movement of the forelimb, and in most cases also during passive manipulation and cutaneous stimulation of the forelimb (compare West et al., 1990). Thus, the loss of firing is not attributable to any compromised ability to sample forelimb neurons or to tissue damage. In addition, firing was later reinstated under certain altered conditions (not studied systematically). This is similar to a previous study in which phasic striatal firing during treadmill locomotion was reinstated after having disappeared after exposure for 30 sessions to an unchanging treadmill cycle (West et al., 1987). The gradual disappearance of striatal firing suggest that movement-related activity may cease during certain movements that have become automatic or habitual, but not before that activity may have contributed to the formulation in other areas (e.g., premotor areas) of computations needed to carry out the automatic movement.

\section{REFERENCES}

Alexander GE (1987) Selective neuronal discharge in monkey putamen reflects intended direction of planned limb movements. Exp Brain Res 67:623-634.

Alexander GE, Crutcher MD (1990a) Preparation for movement: neural representations of intended direction in three motor areas of the monkey. J Neurophysiol 64:133-150.

Alexander GE, Crutcher MD (1990b) Neural representations of the target (goal) of visually guided arm movements in three motor areas of the monkey. J Neurophysiol 64:164-178.

Alexander GE, Delong MR (1985) Microstimulation of the primate neostriatum. II. Somatotopic organization of striatal microexcitable zones and their relation to neuronal response properties. J Neurophysiol 53:1417-1430.

Alexander GE, Delong MR, Crutcher MD (1992) Do cortical and basal ganglionic motor areas use "motor programs" to control movement? Behav Brain Sci 15: 656-665.

Aosaki T, Tsubokawa H, Ishida A, Watanabe K, Graybiel AM, Kimura M (1994) Responses of tonically active neurons in the primate's striatum undergo systematic changes during behavioral sensorimotor conditioning. J Neurosci 4:3969-3984.

Apicella P, Scarnati E, Schultz (1991) Tonically discharging neurons of monkey striatum respond to preparatory and rewarding stimuli. Exp Brain Res 84:672-675.

Brooks VB, (1979) Motor programs revisted. In: Posture and movement (Talbott RE, Humphrey DR, eds), New York: Raven.

Carelli RM, West MO (1991a) Representation of the body by single neurons in the dorsolateral striatum of the awake, unrestrained rat. J Comp Neurol 309:231-249.

Carelli RM, West MO (1991b) Learning-related plasticity of striatal forelimb neurons in the awake, unrestrained rat. Soc Neurosci Abstr 17:1218.

Cho J, West MO 1997 Functional somatotopy shown by single neurons in the lateral striatum of the rat. Brain Res, in press.

Cooke JD (1980) The organization of simple, skilled movements. In: Tutorials in motor behavior (Stelmach GE, Requin J, eds), pp 199-212. North-Holland.

Crutcher MD, Alexander GE (1990) Movement-related neuronal activity selectively coding either direction or muscle pattern in three motor areas of the monkey. J Neurophysiol 64:151-163.

Crutcher MD, Delong MR (1984a) Single cell studies of the primate putamen. I. Functional organization. Exp Brain Res 53:233-243.

Crutcher MD, DeLong MR (1984b) Single cell studies in the primate 
putamen. II. Relations to direction of movement and pattern of muscular activity. Exp Brain Res 53:244-258.

Deadwyler SA, Biela J, Rose G, West M, Lynch G (1979) A microdrive for use with glass microelectrodes in recording from freely-moving rats. Electroencephalogr Clin Neurophysiol 47:752-754.

Dickinson A, (1985) Actions and habits: the development of behavioural autonomy. Philos Trans R Soc Lond [Biol] 308:67-78.

Dolbakyan E, Hernandez-Mesa N, Bures J (1977) Skilled forelimb movements and unit activity in motor cortex and caudate nucleus in rats. Neuroscience 2:73-80.

Ebrahimi A, Pochet R, Roger M (1992) Topographical organization of the projections from physiologically identified areas of the motor cortex to the striatum in the rat. Neurosci Res 14:39-60.

Estes WK (1959) The statistical approach to learning theory. In: Psychology: a study of a science, Vol 2, General systematic formulations, learning, and special processes (Koch, S, ed), pp 380-491. New York: McGraw-Hill.

Everitt BJ, Morris KA, O'Brien A, Robbins TW (1991) The basolateral amygdala-ventral striatal system and conditioned place preference: further evidence of limbic-striatal interactions underlying reward-related processes. Neuroscience 41:1-18.

Flaherty AW, Graybiel AM (1993) Two input systems for body representations in the primate striatal matrix: experimental evidence in the squirrel monkey. J Neurosci 13:1120-1137.

Flaherty AW, Graybiel AM (1994) Input-output organization of the sensorimotor striatum in the squirrel monkey. J Neurosci 14:599-610.

Flowers K (1975) Ballistic and corrective movements on an aiming task: intention tremor and parkinsonian movement disorders compared. Neurology 25:413-421.

Gardiner TW, Nelson RJ (1992) Striatal neuronal activity during the initiation and execution of hand movements made in response to visual and vibratory cues. Exp Brain Res 92:15-26.

Ghez C, Vicario D (1978) The control of rapid limb movement in the cat I. Response latency. Exp Brain Res 33:173-189.

Greene EC (1963) Anatomy of the rat. New York: Hafner.

Hall RD, Lindholm EP (1974) Organization of motor and somatosensory neocortex in the albino rat. Brain Res 66:23-38.

Heindel WC, Butters N, Salmon DP (1988) Impaired learning of a motor skill in patients with Huntington's disease. Behav Neurosci 102:141-147.

Heindel WC, Salmon DP, Butters N (1991) The biasing of weight judgments in Alzheimer's and Huntington's disease: a priming or programming phenomenon? J Clin Exp Neuropsychol 13:189-203.

Hocherman S (1993) Proprioceptive guidance and motor planning of reaching movements to unseen targets. Exp Brain Res 95:349-358.

Hull CL (1943) Principles of behavior. New York: AppletonCentury-Crofts.

Jaeger D, Gilman S, Aldridge JW (1993) Primate basal ganglia activity in a precued reaching task: preparation for movement. Exp Brain Res 95:51-64

Kato M, Kimura M (1992) Effects of reversible blockade of basal ganglia on a voluntary arm movement. J Neurophysiol 68:1516-1534.

Keele SW (1968) Movement control in skilled motor performance. Psychol Bull 70:387-403.

Kimura M (1990) Behaviorally contingent property of movement-related activity of the primate putamen. J Neurophysiol 63:1277-1296.

Kimura M (1992) Behavioral modulation of sensory responses of primate putamen neurons. Brain Res 578:204-214.

Kimura M, Rajkowsi J, Evarts E (1984) Tonically discharging putamen neurons exhibit set-dependent responses. Proc Natl Acad Sci USA 81:4998-5001.

Kimura M, Aosaki T, Ishida A, Watanabe K (1992) Activity of primate putamen neurons is selective to the mode of voluntary movement visually guided, self-intiated or memory guided. Exp Brain Res 89:473-477.

Kimura M, Kato M, Shimazaki H (1990) Physiological properties of projection neurons in the monkey striatum to the globus pallidus. Exp Brain Res 82:672-676.

Knopman D, Nissen MJ (1991) Procedural learning is impaired in Huntington's disease: evidence from the serial reaction time task. Neuropsychologia 29:245-254.

Liles SL (1979) Topographic organization of neurons related to arm movement in the putamen. In: Advances in neurology (Chase TN, ed), pp 155-162. New York: Raven.

Liles SL (1985) Activity of neurons in the putamen during active and passive movements of the wrist. J Neurophysiol 53:217-236.
Ljungberg T, Apicella P, Schultz W (1992) Responses of monkey dopamine neurons during learning of behavior reactions. J Neurophysiol 67:145-163.

Marsden CD (1982) The mysterious motor function of the basal ganglia; the Robert Wartenberg lecture. J Neurol 32:514-539.

Martone M, Butters N, Payne M, Becker JT, Sax DS (1984) Dissociations between skill learning and verbal recognition in amnesia and dementia. Arch Neurol 41:965-969.

McDonald RJ, White NM (1993) A triple dissociation of memory systems: hippocampus, amygdala, and dorsal striatum. Behav Neurosci 107:3-22.

Milner B (1970) Memory and the medial temporal regions of the brain. In: Biology of memory (Pribram KH, Broadbent DE, eds). New York: Academic.

Mirenowicz J, Schultz W (1994) Importance of unpredictability for reward responses in primate dopamine neurons. $\mathbf{J}$ Neurophysiol 72:1024-1027.

Mishkin M, Petri H (1984) Memories and habits: some implications for the analysis of learning and retention. In: Neuropsychology of memory (Butters N, Squire LR, eds), pp 287-296. New York: Guilford.

Mishkin M, Malamut B, Bachevalier J (1984) Memories and habits: two neural systems. In: Neurobiology of learning and memory (Lynch G, MCGaugh JL, Weinberger NM, eds). New York: Guilford.

Mittler T, Cho J, Peoples LL, West MO (1994) Representation of the body in the lateral striatum of the freely moving rat: single neurons related to licking. Exp Brain Res 98:163-167.

Moroz VM, Bures J (1983) A telerecording analysis of reaching disruptions in rats after stimulation or lesion. Physiol Behav 31:255-257.

Olmstead CH, Villablanca JR, Marcus RJ, Avery D (1976) Effects of caudate nuclei or frontal cortex ablations in cats. IV. Bar pressing, maze learning, and performance. Exp Neurol 53:670-693.

Pearce JM, Hall G (1980) A model for Pavlovian learning: variations in the effectiveness of conditioned but not of unconditioned stimuli. Psychol Rev 87:532-552.

Phillips RR, Malamut BL, Bachevalier J, Mishkin M (1988) Dissociation of the effects of inferior temporal and limbic lesions on object discrimination learning with $24 \mathrm{hr}$ intertrial intervals. Behav Brain Res 27:99-107.

Polit A, Bizzi E( (1979) Characteristics of motor programs underlying arm movements in monkeys. J Neurophysiol 42:183-194.

Reading PJ, Dunnett SB, Robbins TW (1991) Dissociable roles of the ventral, medial and lateral striatum on the acquisition and performance of a complex visual stimulus-response habit. Behav Brain Res 45:147-161.

Robbins TW, Cador M, Taylor JR, Everitt BJ (1989) Limbic-striatal interactions in reward-related processes. Neurosci Biobehav Rev 13:155-162.

Robbins TW, Giardini V, Jones GH, Reading P, Sahakian BJ (1990) Effects of dopamine depletion from the caudate-putamen and nucleus accumbens septi on the acquisition and performance of a conditional discrimination task. Behav Brain Res 38:243-261.

Romo R, Schultz W (1990) Dopamine neurons of the monkey midbrain: contingencies of responses to active touch during self-initiated arm movements. J Neurophysiol 63:592-606.

Romo R, Scarnati E, Schultz W (1992) Role of primate basal ganglia and frontal cortex in the internal generation of movements. Exp Brain Res 91:385-395

Sabol KE, Neill DB, Wages SA, Church WH, Justice JB (1985) Dopamine depletion in a striatal subregion disrupts performance of a skilled motor task in the rat. Brain Res 335:33-43.

Saint-Cyr JA, Taylor AE, Lang AE (1988) Procedural learning and neostriatal dysfunction in man. Brain 111:941-959.

Saling M, Sitarova T, Vejsada R, Hnik P (1992) Reaching behavior in the rat: absence of forelimb peripheral input. Physiol Behav 51:1151-1156.

Schultz W, Romo R (1988) Neuronal activity in the monkey straitum during the intiation of movements. Exp Brain Res 71:431-436.

Schultz W, Apicella P, Ljungberg T (1993) Responses of monkey dopamine neurons to reward and conditioned stimuli during successive steps of learning a delayed response task. J Neurosci 13:900-913.

Shuvaev VT, Shefer VI (1995) Structure of neuronal activity of the caudate nucleus of monkeys during decision-making and the realization of the motor program in different variants of a delayed spatial choice task. Neurosci Behav Physiol 25:63-70.

Siegel S, Castellan NJ (1988) Nonparametric statistics for the behavioral sciences. New York: McGraw-Hill. 
Siegfried B, Bures J (1980) Handedness in rats: blockade of reaching behavior by unilateral 6-OHDA injections into substantia nigra and caudate nucleus. Physiol Psychol 8:360-368.

Spence KW (1960) Behavior theory and learning. Englewood Cliffs, NJ: Prentice-Hall.

Squire LR, Knowlton B, Musen G (1993) The structure and organization of memory. Annu Rev Psychol 44:453-495.

West MO, Woodward DJ (1984) A technique for microiontophoretic study of single neurons in the freely moving rat. J Neurosci Methods 11:179-186.

West MO, Michael AJ, Knowles SE, Chapin JK, Woodward DJ (1987) Striatal unit activity and the linkage between sensory and motor events. In: Basal ganglia and behavior: sensory aspects of motor functioning (Schneider JS, Lidsky T, eds) pp 27-35. Toronto: Hans Huber Hogrefe.

West MO, Carelli RM, Cohen SM, Gardner JP, Pomerantz M, Chapin JK, Woodward DJ (1990) A region of the dorsolateral striatum of the rat exhibiting single unit correlations with specific locomotor limb movements. J Neurophysiol 64:1233-1246.

Whishaw IQ, O'Connor WT, Dunnett SB (1986) The contributions of motor complex, nigrostriatal dopamine and caudate-putamen to skilled forelimb use in the rat. Brain 109:805-843.

Zhuravin A, Bures J (1986) Operant slowing of the extension phase of the reaching movement in rats. Physiol Behav 36:611-617. 